\title{
Fatores que comprometem a adoção de tecnologia de informação em empresas cafeeiras
}

\author{
Marcos Eduardo dos Santos \\ Universidade Presidente Antônio Carlos [UNIPAC] \\ José Carlos dos Santos Jesus \\ Universidade Federal de Lavras (UFLA)
}

\begin{abstract}
Resumo
Várias dificuldades têm sido encontradas para se introduzir novas tecnologias entre os produtores de café ao longo do tempo. Assim, este estudo buscou identificar os fatores que comprometem a adoção de tecnologia de informação em empresas cafeeiras. Têm-se como objetos de estudo seis empresas cafeeiras situadas na região Sul de Minas Gerais que adotaram dois sistemas de informação (SIJ. Este estudo foi realizado em três etapas: 1) revisão teórica sobre adoção e resistências à tecnologia e consolidação do modelo teórico de análise; 2) observações, análise documental e entrevistas com o responsável pela área de informática e diretor geral; e 3) entrevistas com os demais diretores e gerentes. Após a comparação dos casos estudados concluiu-se que os fatores que comprometeram o processo de adoção foram categorizados em limitação financeira, baixa formação dos operadores, falta de recursos tecnológicos, incompatibilidade de horários entre instrutor e funcionários, complexidade do software, relação contratual, troca de operadores e instrutores durante a implantação.
\end{abstract}

\section{Palavras-chave}

Tecnologia de informação, cafeicultura, gestão de custos.

\section{Factors that Compromise the Adoption of Information Technologies with Coffee Producers}

\begin{abstract}
Introduction of information technology to coffee producers have been difficult throughout the years. This study intends to identify factors that compromise adoption of the information technology with coffee producers. There were six study objects located in the region Sul de Minas that adopted two information systems. This study was carried out in three stages: 11 revision on adoption and resistance of technology and consolidation of the theoretical analysis model; 2J observations, documentary analysis and interviews with technology supervisor and the general director; 3J interviews with marketing, financing and human resources directors. After comparison of the studied cases it was concluded that: the factors that compromised the adoption process can be summarized as financial limitations, low education level of computer operators, lack of technological resources, incompatibility of schedules between instructor and computer operators, software complexity, work contract failure, substitute of computer operators and instructors during the implementation.
\end{abstract}

Key words

Adoption information technology, producers coffee, cost management. 


\section{INTRODUĈ̣̃O}

Os empresários agrícolas, mais especificamente os cafeicultores, devem intensificar suas ações para a adoção de novas práticas de gestão, incorporando em seus processos a utilização da tecnologia de informação (TI), pois ela possibilita, dentre outros benefícios, prover as informações necessárias à tomada de decisão. Sendo o café um produto historicamente importante no agronegócio brasileiro, é de interesse estudar a adoção de TI por parte dos empresá-

rios do setor cafeeiro.

Dessa forma, este estudo pretende identificar os fatores que comprometem o processo de adoção de tecnologias de informações no setor produtivo cafeeiro. A importância do estudo, portanto, é contribuir para reduzir os problemas e as resistências, que costumam ocorrer no processo de adoção de tecnologias de informação, pelos empresários do setor cafeeiro.

Nesse sentido, pretende-se estudar o processo de adoção de duas tecnologias de informação, "Gestão Administrativa de Fazendas" e "Panha: Sistema de Informação para o Gerenciamento da Colheita", implantadas em seis empresas cafeeiras situadas na região Sul de Minas Gerais.

Especificamente, pretende-se, para cada empresa estudada:

- identificar os motivos que levaram os seus dirigentes a investir em sistemas de informações e as etapas do processo de adoção;

- verificar e descrever resistências e limitações dos indivíduos à implantação dos sistemas e suas dificuldades na utilização efetiva na fase posterior;

- identificar o perfil dos entrevistados segundo o modelo de difusão de inovação tecnológica.

Para tanto, o trabalho está dividido em cinco partes: a presente introdução; a segunda parte, que apresenta a fundamentação teórica; a terceira seção, que apresenta a metodologia de como foi conduzido o estudo; na quarta seção, os resultados e a discussão; e, por fim, as conclusões.

\section{FUNDAMENTACÃO TEÓRICA}

Devido à complexidade do processo de adoção de SIs, uma única medida de avaliação não é suficiente para cobrir todos os fatores que influenciam esta atividade. Nesta pesquisa escolheu-se uma combinação de diferentes abordagens teóricas como meio plausível de definir e superar esta dificuldade.
Sistema de informação e tecnologia da informação

Em relação aos pressupostos da Teoria Geral de Sistemas, Bertalanfy (1975) define sistema de informação (SI) como um sistema aberto, que busca alcançar um determinado objetivo, dinâmico e que produz informação. O mesmo autor ainda complementa a definição afirmando que o SI é composto por três elementos fundamentais: pessoas, procedimentos e dados, ou seja, as pessoas coletam dados e definem procedimentos para que estes dados sejam processados e gerem informações. 
Não se trata de conceber esta tecnologia apenas em termos de computadores, mas sim da união dos recursos da informática e da tecnologia de telecomunicação, também conhecida como teleinformática, como considera Castels (1999).

Dentre os vários autores que buscam conceituar a TI, destacam-se Doyle (1997, p. 17), que a define como o "meio utilizado para processar, transmitir, manipular, analisar e explorar dados e informações", e Campos Filho (1994, p. 36), para quem "é o conjunto de hardware e software que desempenha uma ou mais tarefas de processamento de informações", fazendo parte dos sistemas de informação das organizações, que incluem coleta, transmissão, estocagem, recuperação, manipulação e exibição de dados.

Os sistemas podem ser classificados como sistemas de nível operacional (decisões do tipo quando, onde e quem), quando servem aos gerentes operacionais na definição das atividades elementares e transacionais das organizações, sendo os Sistemas de Informação Transacionais (SIT) os representantes desta categoria. Os sistemas de nível tático ou gerencial têm como função responder às questões do tipo "como fazer" e servem aos gerentes intermediários nas atividades de monitoramento, controle e tomada de decisão, tendo os Sistemas de Informação Gerenciais (SIGs) e Sistemas de Apoio à Decisão (SADs) como representantes neste nível. Já os sistemas de nível estratégico buscam responder às questões do tipo "o que fazer e quanto fazer", e são desenvolvidos de acordo com a análise ambiental da organização. Como categorias têm-se os Sistemas de Informação Estratégica (SIEs) e os Sistemas Especialistas (SEs). O esquema da Figura 2 pode auxiliar na percepção de como os SIs podem ser agrupados segundo a teoria dos níveis de gestão.

\section{Difusão e adoção de inovações tecnológicas}

O paradigma da difusão de inovação tem origem nas pesquisas tradicionais da sociologia rural, iniciada nos anos 1940. A sociologia rural é um subcampo da sociologia voltado para os problemas sociais da vida rural. Ryan e Gross (1943), citados por Rogers \& Scott (1997), foram os primeiros teóricos a estudarem a difusão de inovações;

Figura 1: Componentes e processos constituintes do conceito de SI.

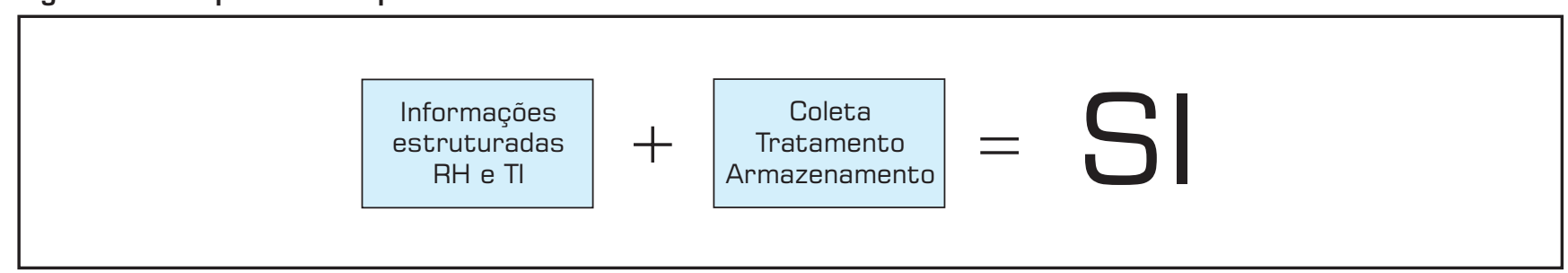

Fonte: elaborado pelo autor (2005).

Figura 2: Sistemas de informações associados aos níveis organizacionais.

\section{SISTEMAS BÁSICOS OU COMPLEMENTARES}

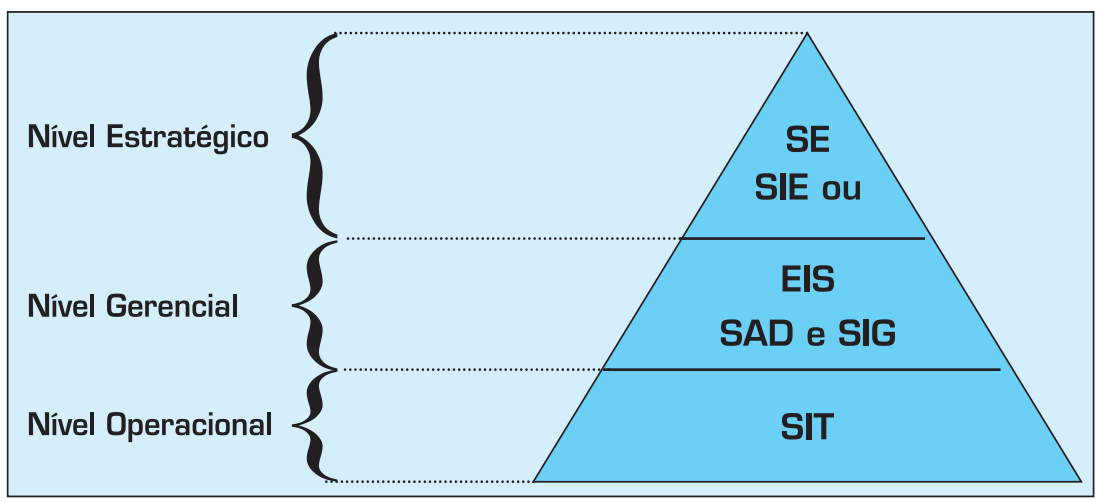

Fonte: adaptado de Meirelles (1994). 
eles investigaram a difusão de milho híbrido entre fazendeiros do Iowa, Estados Unidos, ocorrida de 1928 até 1941. Ryan e Gross perceberam que o estudo poderia servir de lição para que outras inovações pudessem ser difundidas. Desde então, o modelo de difusão tem sido aplicado em uma enorme variedade de disciplinas, como na educação, na saúde pública, na comunicação, no marketing, na geografia, na sociologia geral e na economia.

Difusão, segundo Rogers (1995), é o processo pelo qual uma inovação é comunicada através de certos canais no tempo para os membros de um sistema social.

Para Rogers (1995), o tempo de adoção prévia ou tardia de um usuário ou grupo define a categoria de adotante ou, ainda, a "taxa de adoção", que é a velocidade relativa com que uma inovação é adotada por membros de um sistema social.

À medida que os indivíduos vão adotando uma nova idéia, estes dados de adoção vão sendo plotados numa freqüência cumulativa no tempo. A distribuição resultante é uma curva com formato de S, como visto na Figura 3. Ou seja, no início, apenas alguns poucos indivíduos adotam a idéia (estes são os inovadores). Mas, logo a curva começa a subir, conforme mais e mais pessoas vão adotando a idéia. Eventualmente, a trajetória de adoção começa a enfraquecer, pois poucos indivíduos restam que ainda não adotaram a idéia (são os retardatários) e a curva chega numa assíntota, encerrando-se o processo.

As cinco categorias de adotantes citadas por Rogers \& Scott (1997) são:

- inovadores (innovators) - são os primeiros 2,5\% de indivíduos que estão em contato com a inovação e que assumem os riscos de a utilizarem ou criarem;
- adotadores (early adopters) - são os próximos 13,5\% dos indivíduos em um sistema a adotarem uma inovação. Eles são mais integrados ao sistema local que os inovadores e é a quem os potenciais adotadores pedirão conselho e informação sobre a inovação;

- maioria inicial (early majority) - são os 34 \% dos indivíduos a adotarem uma inovação antes da média das pessoas no sistema;

- maioria tardia (later majority) - são os $34 \%$ de céticos em um sistema. As inovações são recebidas com um ar cauteloso; assim, eles não as adotam até que a maior parte dos indivíduos do sistema tenha aceitado a novidade;

- retardatários (laggards) - representam $16 \%$ de indivíduos. São os últimos a adotarem a nova idéia. Como seus recursos são limitados, eles devem ter a certeza de que uma nova idéia não irá falhar e lhe trará bons resultados.

\section{Resistências e limitações à implantação de tecnologias}

As pessoas e as empresas reagem de maneira muito diferente diante de qualquer mudança tecnológica proposta: algumas ficam fascinadas, outras perplexas; outras ainda estão ou deslumbradas ou totalmente descrentes; há ainda as que as aceitam sem maiores questionamentos e outras que relutam veementemente (SANTOS JÚNIOR, 2002).

Para Almeida (2003), as origens das resistências à tecnologia podem ser assim categorizadas:

- deficiência técnica do sistema implantado - estudos comprovam que mesmo sistemas tecnicamente perfeitos são abandonados após sua implantação, por não atingirem os objetivos desejados;

Figura 3: Curva de adoção de inovações de Rogers.

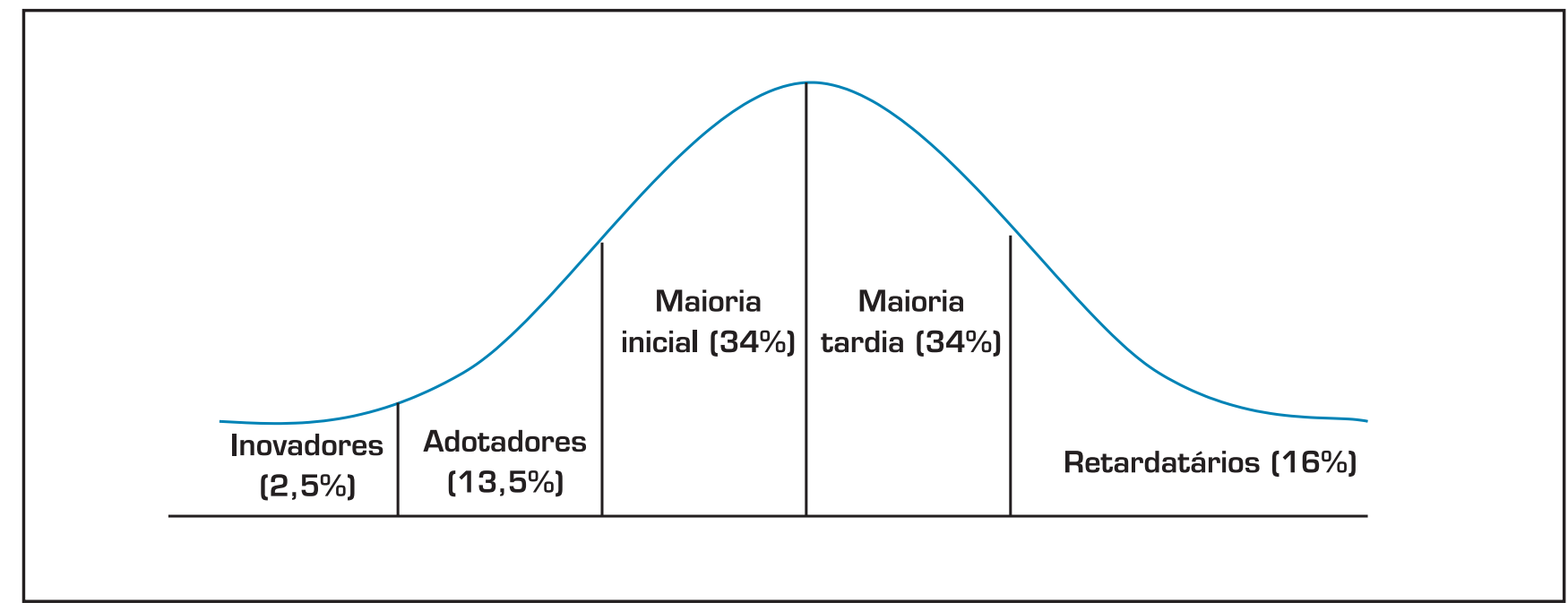

Fonte: Rogers (1995). 
- comportamento individual ou em grupo:

- o indivíduo resiste à mudança porque suas necessidades (proteção contra ameaças e privações) podem ser comprometidas;

- o indivíduo pode acreditar que não é capaz de acompanhar a mudança;

- o indivíduo pode não estar convencido dos objetivos e intenções da introdução da tecnologia;

- o indivíduo resistirá ao processo se sentir que sua posição na organização se encontra ameaçada;

- resistência de um grupo - quando mais de uma pessoa compartilham dos mesmos sentimentos que definem as resistências individuais, elas se agrupam, formando campos de poder para irem contra as mudanças.

Santos Júnior (2002) corrobora com Almeida (2003) ao afirmar que, no contexto geral, fatores sociotécnicos relacionados aos recursos humanos - como necessidade de treinamento, falta de suporte técnico e de políticas motivacionais e a resistência cultural à mudança - são questões a serem resolvidas para uma melhor utilização das TIs disponíveis.

Já Yamaguchi et al. (2002) e Fernández \& Flores-Cerda (2003) apresentam o seguinte conjunto de evidências no setor agrícola que dificultam a implantação das TIs:

- idade média avançada dos empresários agrícolas;

- baixo nível de escolaridade;

- migração dos filhos para outras atividades nas cidades;

- falta de recursos financeiros para aquisição de equipamentos, material de informática e treinamento de pessoal;

- precariedade ou ausência dos serviços de telefonia e energia elétrica;

- ausência de provedores de acesso à Internet;

- falta de visão administrativa dos dirigentes de cooperativas;

- falta de pessoal especializado para desenvolver software operacionalmente funcional para o segmento;

- apreensões dos técnicos em relação ao fato de os Sistemas Especialistas (SEs) futuramente virem a substituí-los;

- tipo de atividade, tamanho e número de funcionários da empresa;

- demanda de arquivamento de documentos.

Componente relevante para inibir resistências durante a adoção de TIs é a metodologia de desenvolvimento de software. Jesus (2002) faz uma reflexão sobre os benefícios de se aliar a pesquisa-ação e a prototipação. Segundo este autor, o uso dessas metodologias colabora para o sucesso no desenvolvimento e implantação de software, pois elas permitem "a participação ativa e responsável dos usuários" em todas as etapas e evoluções do protótipo, além de despertar um sentimento de "paternidade com relação às versões dos protótipos do sistema, pois eram as idéias discutidas que se cristalizavam na forma de um sistema de informação - o filho" (JESUS, 2002, p. 195). Dessa forma, a participação e a compreensão dos envolvidos no processo são de fundamental importância para o sucesso da adoção.

\section{METODOLOGIA}

Do ponto de vista dos procedimentos técnicos, foi utilizada a técnica do estudo de multicaso comparativo, pois envolveu o estudo da adoção de TI em empresas com perfis diferentes. O método comparativo, segundo Triviños (1995), permite evidenciar regularidades ou diferenças entre dois ou mais enfoques específicos. Foi escolhida esta técnica por envolver um estudo profundo e exaustivo de alguns objetos, de maneira a permitir o seu amplo e detalhado conhecimento.

O estudo comparativo dos casos foi realizado em cinco empresas cafeeiras sediadas em Santo Antônio do Amparo e uma empresa situada na cidade de Nepomuceno, ambas no Sul de Minas Gerais, perfazendo um total de seis casos.

A escolha da região se justificou pela sua tradição no cultivo, beneficiamento e comercialização de café. As unidades de análise, no entanto, foram escolhidas levandose em consideração os seguintes critérios:

- adoção dos sistemas de informação "Gestão Administrativa de Fazendas" e "Panha: Sistema de Informação para o Gerenciamento da Colheita"; a exigência destes softwares se justifica por serem dois dos poucos voltados especificamente para a administração de propriedades cafeeiras e pela necessidade do estudo comparativo manter a homogeneidade nas TIs adotadas pelos cafeicultores, de forma a possibilitar a validação na comparação de seu uso;

- consentimento e interesse da empresa na realização da pesquisa.

Considerando a inerente complexidade da realidade, foi conveniente fazer uso de uma combinação de procedimentos, técnicas e instrumentos que proporcionaram ampla cobertura, tanto na seleção de informações quanto na coleta de dados, o que pôde ser viabilizado por intermédio da técnica de triangulação. Segundo Triviños (1995), neste método são empregados vários procedimentos e técnicas satélites, distribuídas em três níveis que circundam o objeto de estudo.

O modelo de coleta de dados deste estudo permeia os níveis citados por Triviños (1995). No nível três, conectou-se o modelo de análise para este estudo ao referencial teórico por intermédio da revisão bibliográfica do tópico 2, no qual foram apresentados os principais temas que envolvem os objetivos da pesquisa, como 
resistências e limitações, que comprometem o sucesso na adoção da TI nas empresas.

O segundo nível da triangulação, intermediário, foca os documentos produzidos pelo meio que Triviños (1995) classifica em seis tipos: externos, internos, legais, oficiais, estatísticos e audiovisuais. Nesta fase da coleta de dados, foram utilizadas as técnicas de observação, análise de documentos (planos, projetos, softwares e relatórios) e a entrevista com o responsável pelo setor de informática e ou gerente. Estes instrumentos permitiram identificar e conhecer o perfil socioeconômico, o processo de informatização e como são processadas, armazenadas e acessadas as informações das empresas em estudo, atingindo-se parte dos objetivos propostos.

No primeiro nível, foca-se o que está mais próximo da realidade observada, esta habitada pelos sujeitos, manancial de onde provém a primeira camada de informações, que devem ser colhidas por meio de instrumentos e técnicas que vasculhem as impressões, as opiniões e as idéias desses sujeitos.

Dentre as várias técnicas propostas para a análise dos dados, optou-se pela utilização da análise de conteúdo (AC) das entrevistas.
Para Bardin (1977, p. 42), a análise de conteúdo é definida como "um conjunto de técnicas de análise das comunicações, visando obter, por procedimentos sistemáticos e objetivos de descrição do conteúdo das mensagens, indicadores que permitam a inferência de conhecimentos relativos às condições de produção/recepção destas mensagens".

Portanto, após a transcrição e digitação das entrevistas, iniciaram-se a análise crítica e a reflexão para, em seguida, fazer o agrupamento dos discursos em categorias. Finalizada essa fase, fez-se o inventário e, a seguir, a classificação por analogias. A partir desse momento, emergiram naturalmente os núcleos de significado ou núcleos de sentido. O núcleo de sentido é a unidade final de compreensão, ou seja, é o que o pesquisador conseguiu abstrair das falas dos atores sociais. É o que havia de oculto, não revelado tacitamente nos discursos.

Apoiando-se na análise de conteúdo e na fundamentação teórica, foi delineado o modelo de análise ilustrado na Figura 4. Este modelo compreende o tema central do estudo, que é a adoção de TI, a qual é influenciada pelas resistências dos indivíduos e algumas limitações, bem como as experiências já vivenciadas em relação à implantação de TIs. Essas categorias foram o arcabouço norteador do estudo.

Figura 4: Modelo de análise do processo de adoção de TI.

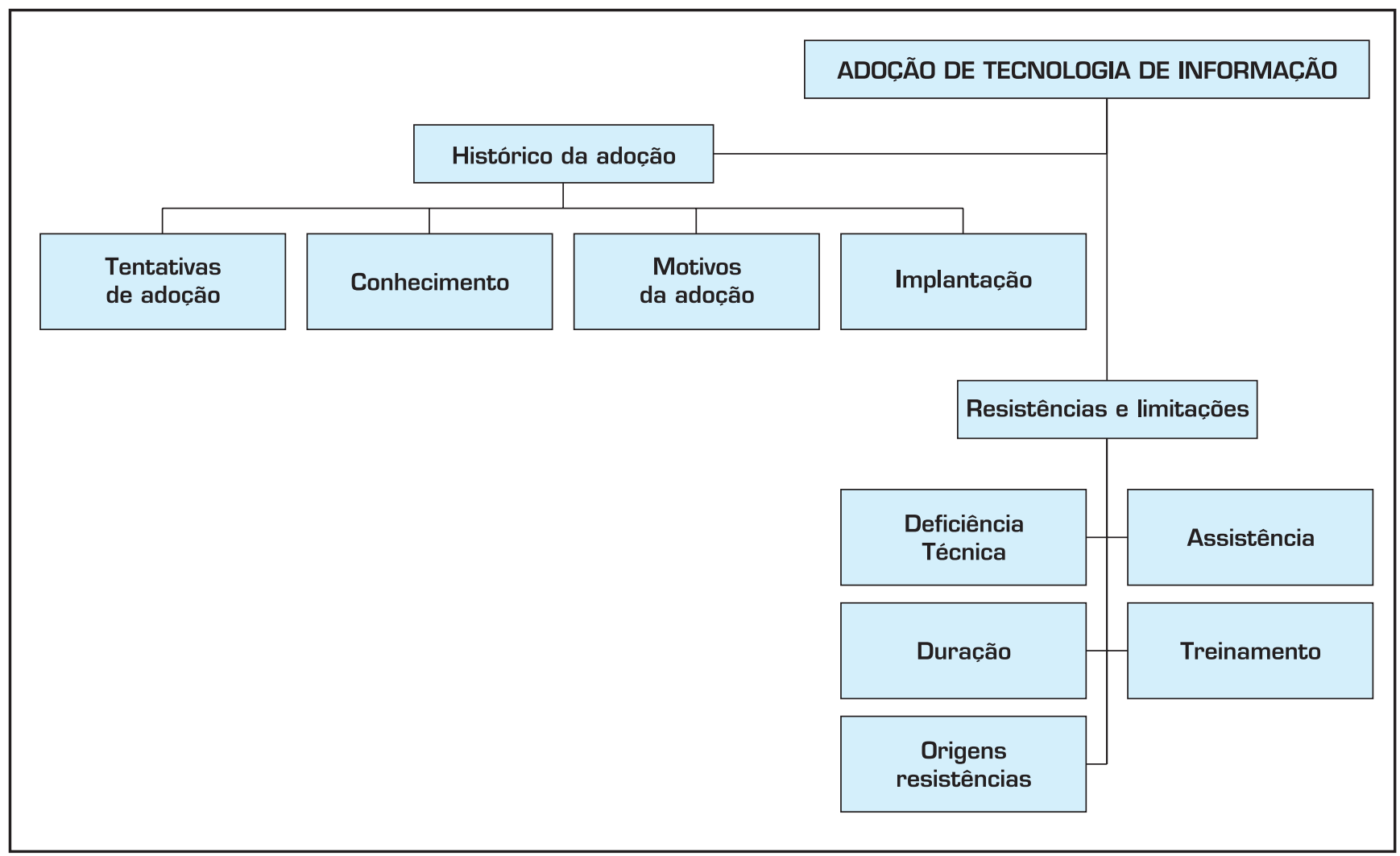

Fonte: elaborado pelo autor, 2005. 


\section{RESULTADOS E DISCUSSÃO}

\section{Perfil socioeconômico}

As empresas estudadas atuam, em média, há 41 anos no negócio produtivo de café. Além desta atividade, as empresas possuem, na maioria dos casos, mais duas, como a pecuária de corte e a produção de milho, respectivamente nessa ordem de importância segundo o faturamento. A área destinada à produção de café de 126 hectares, a produção média de 3.367 sacas e o faturamento anual médio de $\mathrm{R} \$ 1.145 .000$ evidenciam que as empresas pesquisadas são de médio a grande porte. principais "tomadores de decisão" das empresas possuem, no mínimo, o ensino médio completo e, em alguns casos (duas citações), os dirigentes possuem pós-graduação. Estes dados podem ser observados com maiores detalhes no Quadro 1.

\section{Relação contratual entre o desenvolvedor e seus clientes}

Quanto à relação contratual entre as partes (desenvolvedor e clientes), cabe destacar que o desenvolvedor, ao receber uma proposta de venda dos softwares, firma verbalmente com seu cliente não somente o repasse das cópias dos softwares, mas sim uma consultoria gerencial associada a uma solução de informática. Especificamente, o desenvolvedor é um professor universitário que presta seus serviços de consultoria e não possui uma softwarehouse. A razão para isso é a pequena carteira de clientes que inviabiliza os custos de formação de uma empresa. Dessa forma, as relações se dão pelo contrato verbal.

Assim, várias implicações decorrem da falta de um contrato formalizado no qual se especifiquem de forma clara os serviços que de-

A gestão das empresas é de base familiar com uma estrutura pouco hierarquizada, sendo o proprietário, na maioria das vezes, diretor geral da empresa, e a diretoria executiva formada por seus familiares. As empresas não possuem um organograma formal e documentado; a estrutura de cargos é idealizada de forma tal que cada funcionário forma, por si só, uma unidade organizacional.

Nos escritórios das empresas trabalham, em média, dois funcionários, que são responsáveis por auxiliar o gerente de fazendas na administração da propriedade, além da responsabilidade de realizar as entradas e emissão de relatórios dos softwares em estudo.

Cada empresa possui cerca de 35 funcionários fixos desempenhando funções operacionais (ou de campo) e dois funcionários administrativos/direção, com remunerações médias de $\mathrm{R} \$ 300,00$ a $\mathrm{R} \$ 550,00$, respectivamente. Vale ainda observar que a grande maioria dos funcionários estudou até o ensino fundamental, no entanto, os vem ser prestados e seus respectivos custos. Após decorrer algum tempo, o cliente, por desmerecer o contrato verbal e em outros casos esquecer de seu conteúdo, passa a confundir o que realmente foi inicialmente acordado com o que ele acha que foi acordado. A origem desses problemas é identificada em duas categorias:

- treinamento (conteúdo, prazo e valor): o treinamento inicial é fornecido pelo desenvolvedor e expandido pelo "instrutor" nos tópicos de agropecuária e administração de custos. O tempo de duração do treinamento não é prefixado, mas sim dependente da dinâmica do operador sendo treinado. O treinamento é agendado de acordo com a disponibilidade do instrutor, pois ele desempenha, durante a semana, a função de operador 1 . O valor do treinamento é um valor fixo cobrado pelo desenvolvedor e repassado integralmente ao instrutor quando esse realiza o treinamento. Incluem-se nesse valor as despesas de estadia e transporte;

Quadro 1: Relacionamento do número de funcionários por categoria hierárquica e nível de escolaridade.

\begin{tabular}{|l|c|c|c|c|c|c|}
\hline GATEGORIA & ANALFA. & $\begin{array}{c}\text { ENS. FUND. } \\
\text { INCOMPL. }\end{array}$ & $\begin{array}{c}\text { ENS. FUND. } \\
\text { COMPLETO }\end{array}$ & $\begin{array}{c}\text { ENSINO MÉD. } \\
\text { OU TÉCNICO }\end{array}$ & $\begin{array}{c}\text { CURSO SUPERIOR } \\
\text { SUEÁDIA (R\$) }\end{array}$ \\
\hline Campo & $28 \%$ & $65 \%$ & $6 \%$ & $1 \%$ & $0 \%$ & 300 \\
\hline Escritório & $0 \%$ & $0 \%$ & $17 \%$ & $67 \%$ & $17 \%$ & 550 \\
\hline Diretoria & $0 \%$ & $11 \%$ & $11 \%$ & $11 \%$ & $67 \%$ & 3000 \\
\hline
\end{tabular}

Fonte: Dados da pesquisa, 2005. 
- custo de manutenção e custo de desenvolvimento: outra confusão muito comum entre os clientes é a respeito do que seria "manutenção" e o que seria "desenvolvimento". Segundo o desenvolvedor, a manutenção é a alteração/adaptação ou correção de algum módulo dos softwares, bem como o direito de o cliente esclarecer dúvidas com o desenvolvedor ou o instrutor e possui um valor cobrado mensalmente. Já o desenvolvimento representa profundas mudanças na lógica ou até mesmo novos módulos nos softwares, como foi o caso da adição do módulo de "Colheita Mecânica" no software "Colheita", pedido por uma dirigente.

Outra dificuldade da não formalização contratual entre o desenvolvedor e seus clientes seria que, para garantir a legalidade do contrato verbal, tem-se a necessidade de pelo menos duas pessoas como testemunhas no momento da firmação do contrato. Isso poderia dar margem aos mesmos problemas citados anteriormente, caso essas testemunhas não entendam ou não se lembrem do que foi firmado.

Contudo, essa relação informal possibilita, segundo o desenvolvedor, um custo mais baixo para os produtos finais e para os serviços prestados, ao ser descontado o custo do contrato e as demais despesas de manutenção de uma empresa.

Por fim, o desenvolvedor reconhece que, com a constituição de uma sooftwarehouse, haveria um ganho de escala na comercialização dos softwares e na prestação dos serviços de consultoria, aumentando sua carteira de clientes. Com a profissionalização da gestão da empresa seriam percebidas melhorias na assistência aos clientes, pois uma equipe de suporte poderia ser montada. Uma parceria com centros de pesquisa poderia ser realizada a fim de que os dados coletados nos diversos clientes da empresa fossem utilizados como subsídios para a geração de pesquisas científicas.

\section{Análise comparativa dos casos}

Neste subtópico são apresentadas, de forma sintética e com o auxílio de quadros-resumos, as comparações entre os grupos de adotadores das tecnologias de informação em estudo, identificadas no tópico anterior. Estes resultados estão organizados segundo a mesma seqüência das categorias mencionadas no modelo teórico.

\section{Histórico da adoção}

No Quadro 2, percebe-se que, na maioria dos casos (1, 2, 3 e 6), as empresas estudadas já passaram por algum processo de informatização mal implementado, seja por deficiências técnicas dos softwares ou por falta de adap- tação às necessidades dos dirigentes. Apesar disso, os empresários cafeeiros ainda acreditam nas potencialidades da TI, desde que bem direcionada. O desejo de substituir aqueles softwares que não trouxeram os resultados esperados foi um dos principais motivos para a adoção das TIs atuais, seguido pelo controle gerencial e geração de informações sobre indicadores técnicos. Os dirigentes do grupo inovador e adotadores tomaram conhecimento das TIs por sugestão de consultores externos que conheciam as necessidades de seus clientes e a capacidade técnica e profissional do desenvolvedor. Outra fonte de conhecimento a respeito das TIs foi a visita feita pelos dirigentes do grupo maioria inicial à empresária inovadora (Empresa 1). Nessas visitas, os dirigentes puderam avaliar o potencial dos softwares e, em seguida, entraram em contato com o desenvolvedor para a contratação dos serviços.

\section{\estão da informação traz benefícios intangíveis e que também ser levados em consideração.}

Logo após a aquisição dos softwares ocorreu o processo de implantação e treinamento dos funcionários. Nesse item da Tabela 2, percebe-se uma diferenciação na forma de implantação das TIs, pois, no grupo de inovadores e adotadores, após o diagnóstico inicial ocorreu a etapa de desenvolvimento das demandas identificadas no diagnóstico por meio das técnicas pesquisa-ação e prototipação. Já o grupo maioria inicial não teve necessidade desta etapa, pois não demandou nenhuma incrementação/alteração nos softwares. Em seguida ocorreu, para todos os grupos de empresários que adotaram o software "Colheita", o treinamento dos operadores em suas funções básicas. No entanto, nas empresas 1, 2 e 5 houve a necessidade de se substituir os operadores anteriores. $\mathrm{Na}$ empresa 1 , isso foi devido a problemas extraprofissionais; na empresa 2 , foi devido à dificuldade da funcionária em assimilar as funções dos softwares e na empresa 5 houve a substituição em função da necessidade de manter um funcionário exclusivo para operar os softwares. Em etapa seguinte, o desenvolvedor elaborou o plano de contas ajustado a cada empresa.

O custo da adoção das TIs para a empresária inovadora foi de $\mathrm{R} \$ 5.000,00$, incluindo o investimento em equipamentos, softwares durante quatro anos de implantação para o software "Colheita" e dois anos do "Gestão". Para o grupo de adotadores, o investimento total médio foi de $\mathrm{R} \$ 12.500,00$, isto por terem um 
maior número de equipamentos e mais modernos. Já o grupo maioria inicial estima ter investido em TI, em média, um total de R \$ 5.500,00 ao longo da implantação do "Colheita" e do "Gestão". Portanto, percebe-se que, mesmo se levar em consideração as despesas fixas não incluídas pelos empresários como o salário do operador, material de informática, treinamentos e consultorias, os softwares em estudo não tiveram um alto custo em relação aos benefícios alcançados (motivos da adoção que foram plenamente atingidos).

\section{Resistências, limitações e dificuldades}

Os fatores de resistência para a adoção das TIs são ilustrados no Quadro 3. A não percepção de resistências

Quadro 2: Histórico da adoção de Tls.

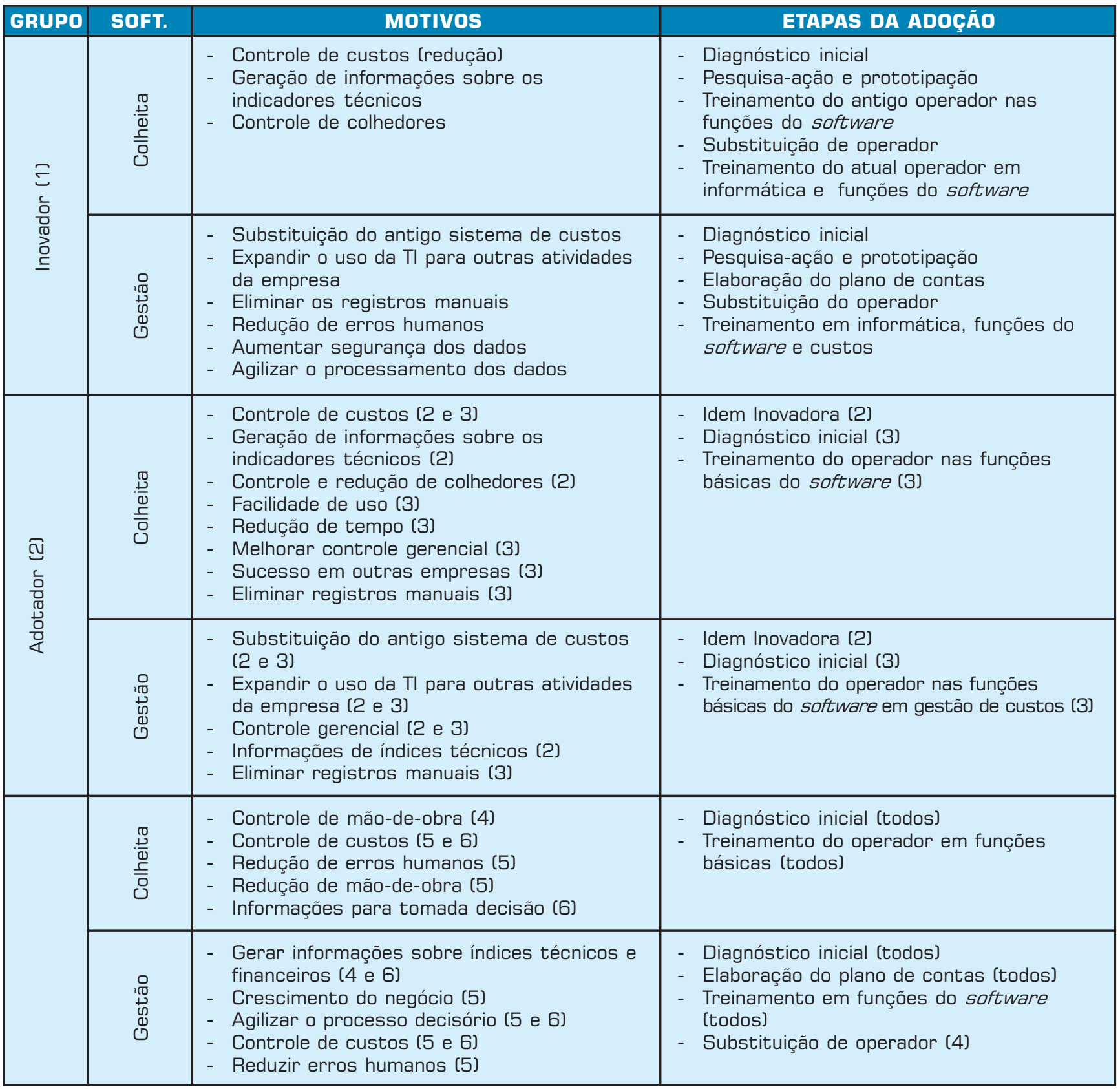

(N) = número de empresários na categoria; $(n)$ = número do caso.

Fonte: Dados da pesquisa, 2005. 
pela maior parte dos empresários é confirmada pela não identificação de fontes de resistências durante as entrevistas com operadores e gerentes administrativos e de produção. No entanto, na empresa inovadora e em uma adotadora, alguns funcionários que não lidam diretamente com os softwares de Colheita e de Gestão manifestaram uma descrença com TIs, isso no início do processo de implantação, talvez por não vislumbrarem de imediato o potencial e os objetivos da mudança. No ambiente administrativo destes mesmos empresários, essa resistência deve-se aos processos anteriores de adoção de TI não satisfatórios; já no nível operacional ou de campo, foi devido à necessidade de adaptação dos funcionários aos novos procedimentos exigidos pela adoção das TIs, como foi o caso da resistência ao uso de crachás.

Os fatores que limitaram ou dificultaram a adoção das TIs pesquisadas foram identificados como sendo: falta de recursos financeiros para contratação de assistência técnica, número de horas semanais reduzido para treinamento, esquecimento ou incompreensão das cláusulas acordadas no contrato verbal, a falta de conhecimento dos funcionários dos processos produtivos das atividades agrícolas, falta de conhecimentos em administração, mais especificamente de administração de custos, baixa escolaridade, complexidade do software "Gestão" e funcionários com receio de assumir novas responsabilidades (Quadro 4). Cabe ainda ressaltar que, após um confronto entre o discurso dos dirigentes e do desenvolvedor, percebeu-se que as dificuldades financeiras, o esquecimento ou a incompreensão das cláusulas acordadas no contrato verbal e a falta de assistência técnica são, na realidade, as mesmas. Isso porque a forma de relação contratual não delimita explicitamente quais são os direitos que os clientes têm mediante o processo de "manutenção" dos softwares. Os empresários entendem que o treinamento e as implementações nos softwares deveriam estar incluídos nessa despesa. Assim, a não remuneração das visitas demandadas pelos clientes inviabiliza o deslocamento do desenvolvedor e do instrutor, apesar de terem comentado que, no treinamento inicial, realizaram várias visitas sem nenhum ônus para os clientes.
Como avaliação geral, o software Gestão foi considerado, pelos empresários, como sendo muito bom e o software "Colheita" excelente, apesar de apenas dois empresários ( 1 e 2 ) terem os objetivos iniciais plenamente atendidos. Os demais empresários que citaram ter seus objetivos iniciais parcialmente atendidos comentaram que esse fato deve-se ao pouco uso do sistema (no máximo 1,5 ano).

\section{\ justificação do investimento em uma certa tecnologia é uma das rimeiras etapas da adoção de Tls.}

De forma complementar, ainda foram mencionadas, pelos empresários, as melhorias sugeridas e implementadas e melhorias que eles desejariam que fossem futuramente implementadas.

Buscando-se ilustrar mais claramente estes fatores, destaca-se o discurso da Diretora Executiva 1, no qual sintetiza duas das categorias anteriormente citadas. Quanto ao fornecedor, ela comenta ser "um profissional que possuía um alto domínio da tecnologia, oferecia o treinamento aos usuários, um bom atendimento e os custos dos serviços e equipamentos serem baixos". Já sobre os softwares, ressalta serem "adequados e customizados em função do ambiente da empresa, flexíveis, de fácil utilização e funcionais".

\section{CONCLUSÕES}

Este trabalho buscou estudar a adoção de duas TIs denominadas "Gestão Administrativa de Fazendas" e "Panha: Sistema de Informação para Gerenciamento da Colheita", implantadas em seis empresas cafeeiras do Sul de Minas Gerais. Mais especificamente, propôs-se identificar motivos, etapas, impactos, resistência, limitações e dificuldades do processo de adoção de tais tecnologias, além de descrever como estão sendo utilizadas pelos empresários.

\section{Quadro 3: Resistências da adoc̣ão de Tls.}

\begin{tabular}{|l|l|c|}
\hline \multicolumn{1}{|c|}{ INOVADOR (1) } & \multicolumn{1}{|c|}{ ADOTADOR (2) } & MAIORIA INICIAL (3) \\
\hline - Descrença de & - Descrença de membro da direção nas Tls (2) & - Nenhuma (todos) \\
funcionários nas Tls & - Funcionários resistentes a novos procedimentos (2) & \\
& - Nenhuma (3) & \\
\hline
\end{tabular}

[N] = número de empresários na categoria; $[n]$ = número do caso.

Fonte: Dados da pesquisa, 2005. 
Nesse sentido, à luz do referencial teórico e dos objetivos pretendidos pelo estudo, os parágrafos a seguir descrevem as conclusões acerca das categorias de significado descritas nos resultados da pesquisa.

\section{Motivos e etapas da adoção das Tls}

A justificação do investimento em uma certa tecnologia é uma das primeiras etapas da adoção de TIs. No entanto, não se pode unicamente pensar em termos financeiros, pois a gestão da informação traz benefícios intangíveis e que também devem ser levados em consideração. Desse modo, no presente trabalho, uma análise multicriterial mostrou-se mais adequada a este tipo de estudo. Assim, foi possível demonstrar que a inflexibilidade de adaptações nos módulos dos softwares, a imposição de novas práticas e o alto custo de manutenção foram os motivos que causaram os fracassos de adoção de TIs anteriores. Portanto, aqueles empresários que já tinham passado por alguma tentativa de informatização manifestaram o desejo de que o atual processo pudesse sanar esses problemas, bem como melhorar o sistema de custo.

Em relação às etapas da adoção, pode-se perceber que as fases do modelo seqüencial foram seguidas em sua plenitude, ou seja, inicialmente, os empresários tomaram conhecimento da inovação por intermédio de consultores que conheciam o desenvolvedor e/ou em conversas com seus vizinhos, e/ou em visita à empresária inovadora (Diretora Executiva 2). Simultaneamente, a partir da exposição do potencial dos softwares, ocorria a fase de persuasão. Em seguida, procuravam o desenvolvedor para confirmar a decisão de implantação. Essa etapa era constituída de visitas do desenvolvedor à propriedade para reformulação do plano de contas, identificação dos recursos tecnológicos e humanos e treinamento inicial. Por fim, a última fase da adoção (confirmação) foi constatada na presente pesquisa ao observar que as expectativas iniciais dos empresários quanto aos softwares foram satisfeitas e, em alguns casos, até mesmo expandidas, o que não deixa de ser um indicador do sucesso da adoção.

\section{Resistências e limitações}

A curta estrutura organizacional e o número reduzido de funcionários administrativos nas empresas estudadas contribuem para o estreitamento das relações interpessoais entre subordinados e direção, possibilitando uma gestão mais democrática e participativa. Como exemplo, tem-se a adoção dos softwares Gestão e Colheita, dos quais muitos operadores participaram não só de todo o processo de adoção, mas enfaticamente da fase de decisão. Esse ambiente, conciliado com a metodologia de adoção, pesquisa-ação, foi fundamental à adoção.

Nesse sentido, as resistências geralmente identificadas na literatura são quase inexistentes nos casos estudados, devido ao fato de todos os indivíduos do sistema social afetados pela adoção terem participado e chegado ao senso comum da mudança proposta. No entanto, resquícios de informatizações malsucedidas geraram desconfianças em alguns indivíduos, mas que talvez serão minimizadas com o uso adequado das TIs ao longo dos próximos anos.

Quadro 4: Limitações e dificuldades da adoção de Tls.

\begin{tabular}{|c|c|c|}
\hline INOVADOR (1) & ADOTADOR (2) & MAIORIA INICIAL (3) \\
\hline $\begin{array}{l}\text { - Falta de recursos } \\
\text { tecnológicos e } \\
\text { financeiros } \\
\text { - Valorização de } \\
\text { cursos técnicos de } \\
\text { produção em } \\
\text { detrimento aos } \\
\text { cursos } \\
\text { administrativos e de } \\
\text { informática }\end{array}$ & $\begin{array}{l}\text { - Falta de recursos financeiros (2) } \\
\text { - } \text { Funcionários sem conhecimento do processo } \\
\text { produtivo das atividades agrícolas e noções } \\
\text { de custeio (2 e 3) } \\
\text { - Poucas horas semanais para treinamento (2) } \\
\text { - Esquecimento ou incompreensão das cláusulas } \\
\text { acordadas com o desenvolvedor (2) } \\
\text { - } \text { treinamento inicial comprometido pela } \\
\text { ineficácia do antigo instrutor [2, З) } \\
\text { - Baixa escolaridade do pessoal de campo (2 e 3) } \\
\text { - Complexidade do software de "Gestão" (2) } \\
\text { - Funcionários com receio de novas } \\
\text { responsabilidades (З) } \\
\text { - Sobrecarga de tarefas do operador (3) }\end{array}$ & $\begin{array}{l}\text { - Limitação financeira (5) } \\
\text { - Falta de conhecimento de custeio do } \\
\text { operador (6) } \\
\text { - Valorização do treinamento técnico } \\
\text { produtivo em detrimento do } \\
\text { administrativo (6) } \\
\text { - Sem infra-estrutura (6) } \\
\text { - Distância entre o dirigente e onde } \\
\text { reside o desenvolvedor (6) } \\
\text { - Despreocupação do dirigente com } \\
\text { cláusulas do contrato [5] } \\
\text { - treinamento inicial comprometido pela } \\
\text { ineficácia do antigo instrutor (5 e 6] } \\
\text { - Queda na produção de café (4) } \\
\text { - Desestímulo com a cafeicultura (4) } \\
\text { - Especificidade de processos internos (5) } \\
\text { - Descomprometimento do operador (6) }\end{array}$ \\
\hline
\end{tabular}

(N) = número de empresários na categoria; $(n)$ = número do caso.

Fonte: dados da pesquisa, 2005. 
Já as limitações da adoção mais percebidas pelos empresários se constituíram em:

- limitação financeira - não se caracteriza apenas como falta de recursos financeiros para a aquisição de novos equipamentos, mas também se manifesta na baixa remuneração dos operadores. Isso se explica, em parte, pela baixa formação ou nível de conhecimento de informática e administração de custos destes funcionários, pois um funcionário com o perfil ideal para operar os softwares (conhecimentos de informática, atividades agropecuárias e de administração de custos) não se sujeitaria aos baixos salários oferecidos pelas empresas estudadas;

- baixa formação dos operadores - derivada da baixa remuneração, já mencionada na limitação financeira;

- falta de recursos tecnológicos - falta de infra-estrutura de telefonia e de provedor de Internet e equipamentos de TI já depreciados;

- incompatibilidade de horários entre o instrutor e os funcionários das empresas para a realização do treinamento - é explicada pela reduzida carteira de clientes do desenvolvedor, impedindo a contratação de mais instrutores ou que $o$ atual instrutor dedique seu tempo exclusivamente a esta atividade;

- complexidade do software "Gestão" - alta se comparada ao software "Panha", mas não comprometeria tanto o processo de adoção se houvesse funcionários com o perfil já mencionado para operar o sistema, pois facilitaria que os procedimentos do software fossem mais facilmente compreendidos;

- relação contratual - descrédito dos clientes para com a validade do contrato verbal, esquecimento e ou incompreensão do que foi acordado (treinamento, custo de manutenção e custo de desenvolvimento) geram problemas de relacionamento entre o desenvolvedor e alguns empresários, apesar de considerarem que o custo da adoção é menor do que se fosse feito por uma empresa formal;

- troca de operadores durante a implantação - mais especificamente na fase de treinamento, comprometeu a rapidez com que os softwares seriam utilizados. Pôde-se ainda perceber que a falta de um funcionário que compartilhe os mesmos conhecimentos do atual operador pode ser crucial se ele não puder executar mais suas atividades, pois, no curto prazo, não haverá quem opere os softwares, além de a empresa ter que arcar novamente com os custos de treinamento;

- ineficiência do antigo instrutor - o processo de adoção ficou durante muitos anos estagnado em algumas empre- sas devido à ineficiência do antigo instrutor em transferir os conhecimentos aos operadores por ele treinados, além de realizar, naquelas empresas, tarefas que não eram de sua competência.

\section{Considerações finais}

A busca pela qualidade em desenvolvimento de software e mais especificamente no êxito da adoção de TIs para o setor produtivo cafeeiro toma atualmente contornos sérios e que foi avaliada na presente pesquisa por meio de uma análise multicriteriosa. Pode-se perceber que os fatores que devem ser levados em consideração em processos de desenvolvimento e adoção de TIs no meio agrícola foram identificados e categorizados como: capacidade de investimento em SI (TI e pessoas) do empresário, remuneração compatível com o nível de formação educacional exigido do operador, profissionalização do fornecedor, softwares adaptados às peculiaridades das empresas.

\section{aixa resistência foi devida ao fato de todos os funcionários terem} participado e chegado ao senso comum da mudança proposta.

É importante destacar que as tecnologias de informação estudadas no presente trabalho se desenvolveram no contexto das relações sociais entre os atores das empresas e o desenvolvedor, o que implica em considerá-las como uma construção resultante da contínua interação entre estes atores com interesses e estratégias diferentes. Daí resulta a situação retratada na pesquisa, em que a metodologia utilizada para a adoção de TIs (pesquisa-ação e prototipação) obteve uma boa aceitação por parte dos interessados, minimizando resistências; impactando positivamente a estrutura, os processos e os recursos humanos; traçando com mais clareza e objetividade as estratégias e políticas de desenvolvimento das empresas e, o mais importante, justificando seu investimento.

Por fim, sugere-se que, em pesquisas futuras, sejam aprofundados os estudos do comportamento das pessoas frente à mudança tecnológica, bem como a adequação de soluções de TI customizadas em vez de "pacotes de gestão" nas pequenas e médias empresas e nas empresas agrícolas, mais especificamente. 


\section{Artigo recebido em 08/07/2005 Aprovado para publicação em 24/11/2005}

\section{- Referências Bibliográficas}

ALMEIDA, F.C. de. Atores e Fatores na Introdução de um Sistema de Informação. Disponível em: http:// www.fia.com.br/proinfo/artigos/. Acesso em: 1 dez. 2003.

ALTER, S. Information Systems: A Management Perspective. 2. ed. Menlo Park: Benjamin e Cummings, 1996.

BARDIN, L. Análise de conteúdo. Lisboa: Edições, 1977.

BERTALANFY, L. von. Teoria Geral dos Sistemas. Petrópolis: Vozes, 1975.

CAMPOS FILHO, M.O. Os sistemas de informação e as modernas tendências da tecnologia e dos negócios. Revista de Administração de Empresa, v. 34, n. 6 (nov./dez.), p. 33-45, 1994

CASTELS, M A Sociedade em Rede: a era da informação - economia, sociedade e cultura. São Paulo: Paz e Terra, 1999.
DOYLE, M.L.F.C.P. Implementação da Tecnologia da Informação: por que a mudança organizacional é necessária? Belo Horizonte: UFMG, 1997. 141 p. (Dissertação de Mestrado).

FERNÁNDEZ, G.L.; FLORES-CERDA $\mathrm{R}$. Individual and Organizational Factors Associated with the Adoption and Use of Computers in Mexican Agribusiness. Disponível em: http:// wcca.ifas.ufl.edu/archive/7thProc/ LOZANO/LOZANO.htm. Acesso em: 1 dez. 2003.

JESUS, J.C. dos S. Sistema de informacão para o gerenciamento da colheita de café: concepção, desenvolvimento, implementação e avaliação dos seus impactos. Rio de Janeiro: COPPE/UFRJ, 2002. 226 p. (Tese de Doutorado).

MEIRELLES, F.S. Informática novas aplicações com microcomputadores. 2. ed. São Paulo: Makron Books, 1994 615 p.
REZENDE, D.A; ABREU, A.F. de. Tecnologia da informação: aplicada a sistemas de informação empresariais São Paulo: Atlas, 2000. p. 61-129.

ROCHA, A. O Essencial dos Sistemas de Informação. Disponível em: http://www.ufp.pt/staf/amrocha/ publica.html. Acesso em: 27 jul. 2001

ROGERS, E.M. Diffusion of Innovations. New York: Free Press, 1995

ROGERS, E.M.; SCOTT, K.L. The Diffusion of Innovations Model and Outreach from the National Network of Libraries of Medicine to Native American Communities. Albuquerque: University of New México, 1997. Disponível em: ht t p://nnlm.gov/pnr/eval/ rogers.html. Acesso em: 1 out. 2004.
SANTOS JUNIOR, S. Fatores Sócio-técnicos Inibidores da Adoção de Modernas Tecnologias de Informação: um estudo exploratório nas pequenas e médias empresas do meio oeste catarinense. Porto Alegre: UFRGS, 2002. (Dissertação de Mestrado).

TAIT, T.F.C. Um modelo de arquitetura de sistemas de informação para o setor público: estudo em empresas estatais prestadoras de serviços de informática. Florianópolis: UFSC, 2000. 227 p. (Tese de Doutorado).

TRIVIÑOS, A.N.S. Introdução a pesquisa em ciências sociais: a pesquisa qualitativa em educação. São Paulo: Atlas, 1995. 175 p

YAMAGUCHI, L.C.T.; CARVALHO, L. de A.; COSTA, C.N. Situação atual, potencialidades e limitações do uso da gestão informatizada em fazendas e cooperativas agropecuárias no Brasil. Disponível em: http://www. agrosoft.com.br/ag2002/workshop/. Acesso em: 10 out. 2002.

- Sobre os autores

\section{Marcos Eduardo dos Santos}

Professor

Universidade Presidente Antônio Carlos (UNIPAC)

Endereço: R. Bernardino Macieira, 260 - 37200-000 - Lavras - MG

Telefone: 3538214423 - 3591111958

E-mail: marcosedbr@yahoo.com.br

\section{José Carlos dos Santos Jesus}

Professor

Universidade Federal de Lavras (UFLA)

Endereço: R. Des. Edésio Fernandes, 425 - 37200-000 - Lavras - MG

Telefone: 3538217812,3538291756 - Fax: 3538291442

E-mail: jcsjesus@ufla.br 